\title{
The Effects of Lidocaine and Verapamil on Overdrive- Induced Suppression of Pacemakers in Dogs with Complete Atrioventricular Block
}

\author{
Ichiro Watanabe, M.D., Satoshi Saito, M.D., \\ Nobuhiro Takahashi, M.D., Naoshi Tanigawa, M.D., \\ Yukio Ozawa, M.D., and Michinobu Hatano, M.D.
}

\section{SUMmary}

When the ventricle is electrically stimulated at a faster rate, the cessation of the drive is followed by a temporary suppression of automaticity (overdrive suppression). The effects of lidocaine and verapamil on overdrive suppression were studied in dogs. Lidocaine slowed the ventricular escape rate and prolonged the pause following overdrive; occasionally, it was about twice the next succeeding RR interval. On the contrary, verapamil influenced neither the ventricular escape rate nor the pause following overdrive. It is suggested that lidocaine not only suppresses the automaticity of ventricular escape pacemaker but also induces exit block and that the spontaneous depolarization of the ventricular pacemaker is not slow channel-dependent.

\section{Additional Indexing Words:}

Ventricular escape rhythm Overdrive suppression Exit block Slow channel dependent activity

7 HIS study was designed to assess the effects of lidocaine and verapamil 1 on ventricular automaticity and the pause following ventricular overdrive in dogs with complete atrioventricular (A-V) block. Our reasons for performing this study were as follows. First, lidocaine is a widely used antiarrhythmic drug in the treatment and prevention of ventricular arrhythmias in acute myocardial infarction. Apart from its well known side effects on the central nervous system, serious conduction disturbances and cardiac arrest have been reported in the literature. ${ }^{1-7)}$ However, its effects on already compromised $\mathrm{A}-\mathrm{V}$ conduction $^{81-10)}$ and impulse formation ${ }^{(1)-15)}$ are equivocal. Second, verapamil has received considerable attention as an antiarrhyth-

From the Second Department of Internal Medicine, Nihon University School of Medicine, Tokyo. Address for reprint: Ichiro Watanabe, M.D., Second Department of Internal Medicine, Nihon University School of Medicine, 30-1, Ooyaguchikamimachi, Itabashi-ku, Tokyo 173, Japan.

Received for publication March 5, 1982.

Manuscript revised July 30, 1982. 
mic agent for supraventricular arrhythmia. Furthermore, verapamil has been shown to prevent the development of ventricular fibrillation during coronary artery ligation in dogs. ${ }^{16}$ ) Zipes and associates ${ }^{17)}$ demonstrated a slowing of the sinus node discharge rate and depression of $\mathrm{A}-\mathrm{V}$ conduction when verapamil was administered to dogs. However, little information is available about the effects of verapamil on ventricular automaticity. ${ }^{18)}$

\section{Methods}

Seventeen mongrel dogs, weighing $11-23 \mathrm{Kg}$, were anesthetized with sodium pentobarbital $(30 \mathrm{mg} / \mathrm{Kg}$, intravenously). A Harvard respirator using room air provided mechanical ventilation through a cuffed endotracheal tube. The temperature of the animals was monitored and maintained at $37^{\circ} \mathrm{C}$ using heat lamps. The aortic pressure and electrocardiographic leads II and $\mathrm{aV}_{\mathbf{F}}$ were recorded on an eight channel, switched-beam oscilloscope. The chest was opened by a right thoracotomy in the fourth intercostal space and the heart was suspended in a pericardial cradle. A bipolar electrode was sutured to the epicardial surface of the right ventricular outflow tract for electrically driving the ventricles. Acute atrioventricular block was induced by injection of $40 \%$ formaldehyde into the region of the bundle of His. ${ }^{19)}$ The ventricle was driven at 60 beats/min between the experimental procedures. Before any procedure was carried out, the ventricular drive was discontinued and sufficient time was allowed for the ventricular escape rate to stabilize. The ventricle was driven for $1 \mathrm{~min}$ at 2 and 4 times the intrinsic rate. The escape rhythm recovery time (ERRT) was measured as the time elapsing from the last driving spike to the first spontaneous ventricular escape beat (Fig. 1).

\section{Lidocaine:}

In 8 dogs, lidocaine was administered into the jugular vein in a bolus of $2 \mathrm{mg} / \mathrm{Kg}$, followed by a constant infusion of $4.3 \mathrm{mg} / \mathrm{Kg} / \mathrm{hour}$.

Verapamil:

In 9 dogs, verapamil was administered into the jugular vein in a bolus of $0.2 \mathrm{mg} / \mathrm{Kg}$, followed by a constant infusion of $0.005 \mathrm{mg} / \mathrm{Kg} / \mathrm{min}$.

The results are expressed as a mean $\pm \mathrm{SE}$ and were analyzed with Student's paired t-test. $P$ values of 0.05 or less were considered significant.

\section{Results}

1. Effects of lidocaine

The average ventricular escape rate was $52.3 \pm 3.7$ beats/min before and 

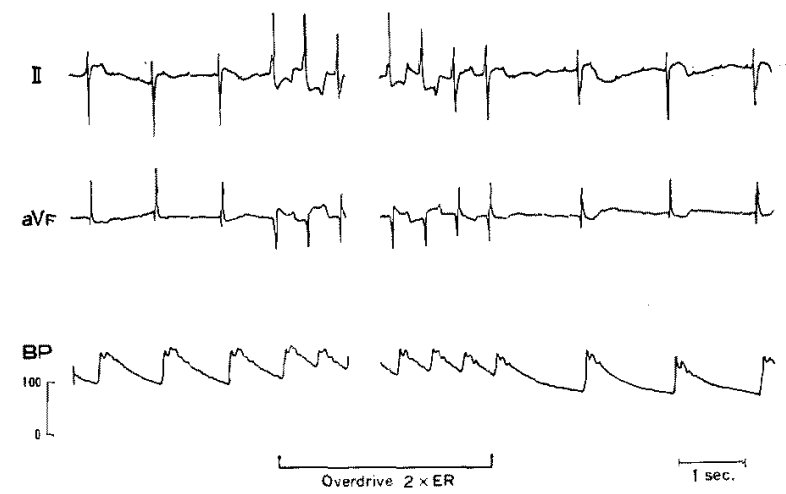

Fig. 1. Suppression of ventricular automaticity by overdrive. II, a $V_{F}$ $=$ lead $\mathrm{II}$ and $\mathrm{a} \mathrm{V}_{\mathrm{F}}$ of the standard $\mathrm{EGG} . \mathrm{Bp}=$ aortic blood pressure tracing; the vertical bar at the left of the blood pressure trace shows the calibration for the blood pressure in $\mathrm{mmHg}$. $E R=$ ventricular escape rate. The period of drive $(1 \mathrm{~min})$ is indicated by the arrows.

Table I. Effects of Lidocaine on Ventricular Automaticity and Overdrive Suppression

\begin{tabular}{|c|c|c|c|c|c|c|}
\hline \multirow[b]{2}{*}{ Expt. } & \multicolumn{3}{|c|}{ Control } & \multicolumn{3}{|c|}{ Lidocaine } \\
\hline & $\begin{array}{c}\text { ER } \\
\text { (beats/min) }\end{array}$ & $\begin{array}{c}\text { Drive } 2 \times \text { ER } \\
\text { ERRT }(\mathrm{sec})\end{array}$ & $\begin{array}{c}\text { Drive } 4 \times \text { ER } \\
\text { ERRT }(\mathrm{sec})\end{array}$ & $\begin{array}{c}\text { ER } \\
\text { (beats/min) }\end{array}$ & $\begin{array}{c}\text { Drive } 2 \times \text { ER } \\
\text { ERRT }(\mathrm{sec})\end{array}$ & $\begin{array}{c}\text { Drive } 4 \times \text { ER } \\
\text { ERRT }(\mathrm{sec})\end{array}$ \\
\hline 1 & 56 & 1.50 & 2.96 & 47 & 2.08 & 9.96 \\
\hline 2 & 65 & 1.44 & 2.18 & 44 & 2.99 & 3.45 \\
\hline 3 & 57 & 1.89 & 2.47 & 48 & 7.59 & 9.63 \\
\hline 4 & 58 & 2.49 & 3.40 & 35 & 4.21 & 8.75 \\
\hline 5 & 53 & 1.86 & 4.82 & 45 & 3.07 & 8.91 \\
\hline 6 & 53 & 1.93 & 4.84 & 36 & 3.38 & 11.22 \\
\hline 7 & 27 & 2.99 & 4.07 & 19 & 7.24 & 15.26 \\
\hline 8 & 49 & 1.45 & 1.56 & 36 & 2.84 & 4.40 \\
\hline Mean & 52.3 & 1.94 & 3.29 & $38.8^{*}$ & $4.18 \dagger$ & $8.95 \dagger$ \\
\hline $\mathrm{SE}$ & 3.7 & 0.18 & 0.40 & 3.2 & 0.69 & 1.23 \\
\hline
\end{tabular}

Expt. =identifying number; $E R=$ ventricular escape rate; $E R R T=$ escape rhythm recovery time, measured as the elapsed time from the last driving spike to the first spontaneous ventricular cscapc beat. Mean $\pm S E=$ Mean values \pm standard error. All hearts driven for $1 \mathrm{~min}$ at 2 and 4 times the ventricular escape rate.

${ }^{*} \mathrm{p}<0.001+\mathrm{p}<0.01$

$38.8 \pm 3.2$ beats $/ \mathrm{min}$ after lidocaine administration (Table $\mathrm{I}, \mathrm{p}<0.001$ ). The mean aortic pressure was not affected by lidocaine $(53.5 \pm 5.7 \mathrm{mmHg}$ versus $50.6 \pm 6.5 \mathrm{mmHg}$ ). The ERRT following ventricular drive at twice the ventricular escape rate was $1.94 \pm 0.18 \mathrm{sec}$ before and $4.18 \pm 0.69 \mathrm{sec}$ after lidocaine administration (Table $\mathrm{I}, \mathrm{p}<0.01$ ). At 4 times the ventricular escape rate, the ERRT was $3.29 \pm 0.40 \mathrm{sec}$ beforc and $8.95 \pm 1.23 \mathrm{sec}$ after 

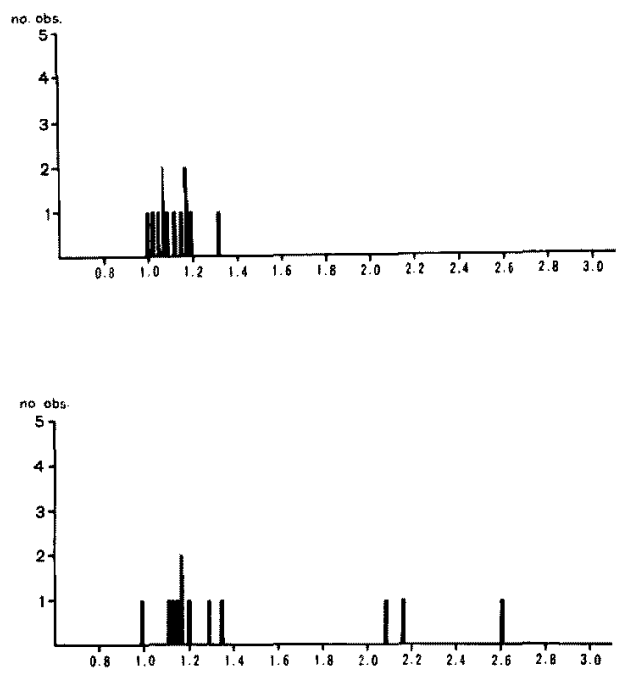

Fig. 2. The ratio between escape rhythm recovery time and the next $R R$ interval during recovery from pacing-induced overdrive suppression. Upper panel; control study, the ratio clustered around $1.1: 1$. With lidocaine (lower panel), two populations are seen, one with a mean ratio about 1.2:1 and one with a ratio greater than $2.0: 1$. no. obs. $=$ number of observations.

Table II. Effects of Verapamil on Ventricular Automaticity and Overdrive Suppression

\begin{tabular}{|c|c|c|c|c|c|c|}
\hline \multirow[b]{2}{*}{ Expt. } & \multicolumn{3}{|c|}{ Control } & \multicolumn{3}{|c|}{ Verapamil } \\
\hline & $\begin{array}{c}\mathrm{ER} \\
\text { (beats/min) }\end{array}$ & $\begin{array}{c}\text { Drive } 2 \times \mathrm{ER} \\
\text { ERRT }(\mathrm{sec})\end{array}$ & $\begin{array}{c}\text { Drive } 4 \times \text { ER } \\
\text { ERRT }(\sec )\end{array}$ & $\begin{array}{c}\mathrm{ER} \\
\text { (beats/min) }\end{array}$ & $\begin{array}{c}\text { Drive } 2 \times \text { ER } \\
\text { ERRT }(\mathrm{sec})\end{array}$ & $\begin{array}{c}\text { Drive } 4 \times \text { ER } \\
\text { ERRT }(\mathrm{sec})\end{array}$ \\
\hline 1 & 34 & 3.01 & 4.13 & 35 & 2.68 & 2.45 \\
\hline 2 & 65 & 1.07 & 1.09 & 64 & 1.17 & 1.24 \\
\hline 3 & 44 & 1.90 & 2.84 & 39 & 1.66 & 2.09 \\
\hline 4 & 58 & 2.35 & 5.34 & 56 & 1.61 & 1.58 \\
\hline 5 & 50 & 1.40 & 1.76 & 58 & 1.29 & 1.29 \\
\hline 6 & 52 & 1.74 & 1.57 & 44 & 2.24 & 2.59 \\
\hline 7 & 54 & 1.61 & 1.53 & 57 & 1.50 & 1.47 \\
\hline 8 & 52 & 2.92 & 7.98 & 48 & 1.75 & 3.25 \\
\hline 9 & 58 & 1.95 & 2.48 & 50 & 4.37 & 5.68 \\
\hline Mean & 51.9 & 1.99 & 3.19 & 50.1 & 2.03 & 2.40 \\
\hline $\mathrm{SE}$ & 2.8 & 0.21 & 0.71 & 3.0 & 0.31 & 0.44 \\
\hline
\end{tabular}

Abbreviations are as in Table I.

lidocaine administration (Table $\mathrm{I}, \mathrm{p}<0.01$ ). Before lidocaine administration, the ratio between ERRT and the next RR interval clustered around 1.1:1 (average 1.11:1, SD 0.0008) (Fig. 2). After lidocaine administration, the ratio between ERRT and the next RR interval clustered around 1.2: 1 in 9 experiments, however, it was greater than $2.0: 1$ in 3 experi- 
ments (exp 1,6,7) (Fig. 2). This gave the impression that one QRS in these 3 cases was missing and that ERRT therefore was approximately doubled.

2. Effects of verapamil

The average ventricular escape rate was $51.9 \pm 2.8$ beats/min before and $50.1 \pm 3.0$ beats/min after verapamil administration (Table II, NS). The ERRT following ventricular drive at twice the ventricular escape rate was $1.99 \pm 0.21 \mathrm{sec}$ before and $2.03 \pm 0.31 \mathrm{sec}$ after verapamil administration (Table II, NS), and at 4 times the ventricular escape rate the ERRT was $3.19 \pm 0.71 \mathrm{sec}$ before and $2.40 \pm 0.44 \mathrm{sec}$ after verapamil administration (Table II, NS). The mean aortic pressure decreased from $55.3 \pm 2.3 \mathrm{mmHg}$ to $47.7 \pm 2.2 \mathrm{mmHg}$ after verapamil administration $(p<0.02)$.

\section{Discussion}

\section{Lidocaine}

It is generally believed that the use of lidocaine is contraindicated in patients with complete A-V block. This opinion is based on studies showing that (1) lidocaine suppressed diastolic depolarization in Purkinje fibers, ${ }^{20)-22)}$ (2) lidocaine slowed the ventricular rate in dogs with surgically induced A-V block, ${ }^{13)}$ and (3) 3 patients with A-V block developed prolonged asystole when the pacemaker was switched off after lidocaine administration. ${ }^{12)}$ However, Roos and Dunning ${ }^{14)}$ reported that an intravenous bolus injection of $100 \mathrm{mg}$ of lidocaine caused no slowing of the rate of the escape rhythm in the 5 patients with a complete A-V block. Furthermore, Aravindaksham et al ${ }^{15}$ ) reported that lidocaine caused either no or slight and transient slowing of the ventricular escape rate in 13 of 18 patients with a complete A-V block distal to the His bundle potential. They postulated that the ventricular escape pacemaker was due to slow channel-dependent activity and that the ventricular escape rate slowed abruptly in a manner suggesting $2: 1$ or $3: 1$ exit block in the remaining 5 patients. In our study, lidocaine slowed the ventricular escape rate and prolonged ERRT. In 3 experiments, the ERRT was about twice the next RR interval suggesting an exit block as the mechanism for this prolongation of ERRT. ${ }^{23), 24 \prime}$

2. Verapamil

Cellular electrophysiological studies have shown that verapamil has no effect on normal Purkinje fiber pacemakers. ${ }^{24,25)}$ However, Hogan and Spitzer ${ }^{26)}$ demonstrated that overdrive suppression in electrically driven Purkinje fibers is diminished by verapamil. In isolated blood-perfused canine papillary muscles, verapamil changed the ventricular rate in a biphasic manner, but the changes remained as small as about $10 \%$ of the basal rate 
in doses which markedly suppressed the force of contraction. ${ }^{27)}$ In vivo, our study showed that the ventricular escape rate and ERRT are nor altered by verapamil. Therefore, the ventricular escape pacemaker is not due to slow channel-dependent activity such as the spontaneous activity found in mitral valve leaflets, ${ }^{28}$ ) the transient low amplitude depolarization caused by digitalis ${ }^{29)}$ and the spontaneous activity in ventricular muscle induced by depolarizing current. ${ }^{30), 31)}$

\section{REFERENCES}

1. Jewitt DE, Kishon $Y$, Thomas $\mathbf{M}$ : Lidocaine in the management of arrhythmias after myocardial infarction. Lancet $1: 266,1978$

2. Flensted-Jensen E, Sandøe E: Lidocaine as an anti-arrhythmic agent. Acta Med Scand 185: 297,1969

3. Gianelly R, Von der Groeben JO, Spitact AP, Harrison DC: Effect of lidocaine on ventricular arrhythmias in patients with coronary heart disease. New Engl J Med 277: 1215, 1967

4. Lown B, Vassaux C: Lidocaine in acute myocardial infarction. Am Heart J 76: 586, 1968

5. Lippestad CTh, Forfang K: Production of sinus arrest by lidocaine. Br Med J 1: 537, 1971

6. Jeresaty RM, Kahn AH, Landry AB Jr: Sino-atrial arrest due to lidocaine in a patient receiving quinidine. Chest 61: 683, 1972

7. Wood RA: Sino-atrial arrest: an interaction between phenytoin and lignocaine. Br Med J $1: 645,1971$

8. Gupta PK, Lichstein E, Chadda KD: Lidocaine-induced heart block in patients with bundle branch block. Am J Cardiol 33: 550, 1974

9. Bekheit S, Murtagh JG, Fletcher E: Effect of lignocaine on conduction system of human heart. Br Heart J 35: 305, 1973

10. Kunkel F, Rowland M, Scheinman MM: The electrophysiological effects of lidocaine in patients with intraventricular conduction defects. Circulation 49: 894, 1974

11. Hayers JG, Ettinger E, Wanat FE, Killip T: Evaluation of lidocaine in the treatment of ventricular arrhythmia. Circulation 35-36 (Suppl II): 137, 1967

12. Ryden L, Korsgren M: The effect of lignocaine on the stimulation threshold and conduction disturbances in patients with pacemaker. Cardiovasc Res 3: 415, 1969

13. Sugimoto T, Schaal SF, Dunn NM, Wallace AG: Electrophysiologic effects of lidocaine in awake dogs. J Pharmacol Exp Ther 166: 146, 1969

14. Roos JC, Dunning AJ: Effects of lidocaine on impulse formation and conduction defects in man. Am Heart J 89: 686, 1975

15. Aravindaksham V, Kuo CS, Gettes LS: Effect of lidocaine on escape rate in patients with complete atrioventricular block. Am J Cardiol 40: 177, 1977

16. Kaumann AJ, Aramendia P: Prevention of ventricular fibrillation induced by coronary ligation. J Pharmacol Exp Ther 164: 326, 1968

17. Zipes DP, Fischer JC: Effects of agents which inhibit the slow channel on sinus node automaticity and atrioventricular conduction in the dog. Circulat Res 34: 184, 1974

18. Endoh M, Yanagisawa T, Taira N: Effects of calcium-antagonistic coronary vasodilators; nifedipine and verapamil, on ventricular automaticity of the dogs. Arch Pharmacol 302: 235,1978

19. Steiner C, Kovalik ATW: A simple technique for production of chronic complete heart block in dogs. J Appl Physiol 25: 631, 1968

20. Bigger JT, Mandel WJ: Effect of lidocaine on the electrophysiological properties of ventricular muscle and Purkinje fibers. J Clin Invest 49:63, 1970 
21. Weld FM, Bigger JT: The effect of lidocaine on diastolic transmembrane currents determining pacemaker depolarization in cardiac Purkinje fibers. Circulat Res 38: 203, 1976

22. Davis LD, Temte JV: Electrophysiological actions of lidocaine on cardiac ventricular muscle and Purkinje fibers. Circulat Res 24: 693, 1969

23. Grendahl H, Miller M, Kjekshus J: Overdrive suppression of implanted pacemakers in patients with AV block. Br Heart J 40: 106, 1978

24. Grendahl H, Kjekshus J, Soyland E, Sivertssen E: Escape rhythm in complete A-V block. PACE 2: 455, 1979

25. Rosen MR, Ilvento JP, Gelband H, Merker C; Effects of verapamil on electrophysiologic properties of canine cardiac Purkinje fibers. J Pharmacol Exp Ther 189: 414, 1974

26. Dersham GH, Han J: Effects of verapamil on action potentials of Purkinje fibers. J Electrocardiol 13: 67,1980

27. Hogan PM, Spitzer KW: Verapamil-induced increases in Purkinje fiber automaticity (abstr). Fed Proc 34: 375, 1975

28. Wit AL, Crancfield PF: Triggered automaticity in cardiac muscle fibers of the simian mitral valve. Circulat Res 38: 85, 1975

29. Rosen MR, Wit AL, Hoffman BF: Electrophysiology and pharmacology of cardiac arrhythmia. IV. Cardiac anti-arrhythmic and toxic effect of digitalis. Am Heart J 89: 391, 1975

30. Grant AO, Katzung BG: The effects of quinidine and verapamil on electrically induced automaticity in the ventricular myocardium of guinea pig. J Pharmacol Exp Ther 196: 407, 1976

31. Imanishi S, McAllister RG Jr, Surawicz B: The effects of verapamil and lidocaine on the automatic depolarizations in guinea-pig ventricular myocardium. J Pharmacol Exp Ther 207: 294, 1978 